\title{
Variação de proteínas séricas em bezerros das raças nelore e holandesa do nascimento até os seis meses de vida
}

\section{Serum proteins variation in Nelore and Holstein calves from birth to six months}

\author{
Evandro Doine Vettorato ${ }^{1}$; Marcio Carvalho da Costa ${ }^{2}$; \\ Karina Keller Marques da Costa Flaiban³; Odilon Vidotto4; \\ Mara Regina Stipp Balarin ${ }^{5}$; Júlio Augusto Naylor Lisbôa ${ }^{5 *}$
}

\section{Resumo}

Estudos anteriores comprovaram que a produção ativa de imunoglobulinas é mais tardia em bezerros Nelore do que nos das raças Canchim ou Limousin, caracterizando possível diferença fisiológica entre zebuínos e taurinos. Esse trabalho tem o objetivo de comparar o proteinograma sérico de bezerros Nelore e Holandeses até os seis meses de vida. Amostras de sangue foram colhidas de 50 bezerros aparentemente sadios, 30 da raça Nelore e 20 da raça Holandesa, entre 24 e 36 horas de vida e aos $15,30,60,90,120,150$ e 180 dias. Determinaram-se as concentrações séricas de proteína total por colorimetria, das frações albumina, alfa, beta e gamaglobulinas por eletroforese em gel de agarose e de IgG estimada por meio do método de turvação pelo sulfato de zinco. Empregou-se a análise de variância de medidas repetidas. A transferência de imunidade passiva foi bem sucedida nos bezerros das duas raças e as variações das proteínas séricas obedeceram a um padrão de comportamento fisiológico ao longo dos seis primeiros meses de vida. A curva de variação das gamaglobulinas representou a principal diferença entre as raças. As concentrações mais elevadas ao término do primeiro dia de vida declinaram até os valores mais reduzidos aos 60 dias na raça Nelore e aos 30 dias na raça Holandesa. A elevação subsequente resultante da produção ativa de anticorpos foi mais precoce nos bezerros Holandeses (a partir dos 60 dias de vida) e mais tardia nos Nelore (a partir dos 90 dias de vida), o que indica que o desenvolvimento da capacidade de imunidade ativa pode ser de fato mais lento em zebuínos do que nos taurinos.

Palavras-chave: Transferência de imunidade passiva, imunidade ativa, gamaglobulina, IgG, zebuínos, taurinos

\footnotetext{
Abstract

Previous studies showed that Nelore calves' active production of immunoglobulins is delayed compared to Canchim and Limousin calves, characterizing a possible physiologic difference between taurine and Zebu calves. In this study we compared serum proteins of Nelore and Holstein calves from birth to six months old. Blood samples were taken from 50 healthy calves (30 Nelore and 20 Holstein) in the

1 Médico Veterinário autônomo. E-mail: italianovett@yahoo.com.br

2 Discente de Doutorado do Department of Clinical Studies Ontario Veterinary College University of Guelph, Canadá. E-mail: costam@uoguelph.ca

3 Prof ${ }^{a}$ Adjunto do Dept ${ }^{\circ}$ de Clínicas Veterinárias, Centro de Ciências Agrárias, Universidade Estadual de Londrina, UEL, Londrina, PR. E-mail: kkflaiban@uel.br

4 Prof. Titular do Dept ${ }^{\circ}$ de Clínicas Veterinárias, CCA/UEL, Londrina, PR. E-mail: vidotto@uel.br

5 Profs. Associado(s) do Dept ${ }^{\circ}$ de Clínicas Veterinárias, CCA/UEL, Londrina, PR. E-mail: marastipp@uol.com.br; janlisboa@uel.br Autor para correspondência
} 
following ages: 24 to 36 hours of life, and 15, 30, 60, 90, 120, 150 and 180 days. Serum total protein concentrations were measured by colorimetry; albumin, alfa, beta and gammaglobulin concentrations were measured by agarose gel electrophoresis; and $\mathrm{IgG}$ concentrations were estimated by the zinc sulphate turbidity test. A repeated measure ANOVA was used to test age effect. The passive transfer of immunity was successful in both breeds and the variation of serum proteins followed the normal pattern throughout the first six months of life. There were breed differences in serum gammaglobulin concentrations. The levels of gammaglobulin were higher at the end of the first day of life, and decreased to the lowest levels at 60 days in Nelore calves and 30 days in Holstein calves. The increase due to the active production of antibodies was precocious in Holstein calves (beginning at 60 days) and slower in Nelore calves (beginning at 90 days), demonstrating that Zebu calves can, in fact, develop active immunity capability later than taurine calves.

Key words: Passive transfer of immunity, active immunity, gammaglobulins, IgG, Zebu, taurine

\section{Introdução}

As proteínas apresentam grande variação fisiológica na circulação sanguínea dos bezerros nos primeiros meses de vida e isto se deve, principalmente, à variação da concentração das gamaglobulinas. A concentração quase nula ao nascimento se eleva ao término do primeiro dia de vida como conseqüência da absorção das imunoglobulinas colostrais, caracterizando o sucesso do processo de transferência de imunidade passiva (TIP). Segue-se a isso inicialmente uma queda como resultado da degradação, distribuição ou utilização dessas proteínas de origem materna, e posteriormente uma elevação gradativa resultante da produção ativa de anticorpos pelo sistema imunológico cada vez mais capacitado (KANEKO, 1997; TIZARD, 2002; CHASE; HURLEY; REBER, 2008).

Os estudos sobre a TIP são numerosos em bezerros de leite da raça Holandesa e a curva de variação das gamaglobulinas nos primeiros meses de vida já está bem caracterizada (MORAES et al., 1997; BORGES et al., 2001; FEITOSA et al., 2001a; PAULETTI et al., 2002; LEAL et al., 2003; RIZZOLI et al., 2006; COSTA et al., 2007). As informações sobre o assunto em bezerros de corte da raça Nelore estão disponíveis em número menor (MACHADO NETO; D'ARCE, 1979; FAGLIARI et al., 1998; AMORIM, 2002; MACHADO NETO et al., 2004; COSTA et al., 2008).
Confrontando-se as curvas de variação traçadas nos diferentes estudos, parece evidente que os bezerros Nelore exibem elevação das gamaglobulinas circulantes mais tardia do que os bezerros Holandeses. Quando comparados aos bezerros das raças Canchim (MACHADO NETO et al., 2004) ou Limousin (COSTA et al., 2008) essa diferença foi comprovada de fato, caracterizando uma possível distinção entre taurinos e zebuínos no desenvolvimento da capacidade de produção ativa de anticorpos.

A única investigação que comparou o proteinograma de bezerros Nelore e Holandeses se limitou ao período entre o nascimento e os 45 dias de idade (FAGLIARI et al., 1998). Esse estudo foi desenvolvido com o objetivo de investigar a variação fisiológica dos componentes do proteinograma no soro sanguíneo de bezerros do nascimento até os seis meses de vida e de estabelecer comparação entre as raças Holandesa e Nelore.

\section{Material e Métodos}

Foram selecionados aleatoriamente 50 bezerros aparentemente sadios e frutos de partos eutócicos, sendo 30 da raça Nelore e 20 da raça Holandesa. Os bezerros da raça Nelore pertenciam a uma única propriedade que adotava boas práticas de manejo nutricional e sanitário, e controle com identificação individual do plantel. Os animais eram manejados extensivamente e recebiam suplementação mineral à vontade. Os bezerros eram mantidos em contato 
permanente com as suas mães desde o nascimento e realizavam mamada natural do colostro. A desmama somente ocorria aos sete ou oito meses de idade. Os bovinos eram observados duas vezes por dia para identificação da manifestação de doenças ou outras ocorrências.

As bezerras da raça Holandesa pertenciam a duas granjas produtoras de leite que igualmente adotavam identificação dos indivíduos e padrão adequado de manejo nutricional e sanitário. Foram incluídos no estudo dez bezerros de cada uma das granjas. $\mathrm{Na}$ primeira propriedade, os bezerros recém-nascidos permaneciam com as suas mães por três a seis horas, e posteriormente eram separados. Se dentro de duas horas após o nascimento não ocorresse a ingestão voluntária do colostro, realizava-se a administração do mesmo por meio de mamadeira (dois litros para cada bezerro), obtido por ordenha da própria vaca ou, se necessário, de um banco de colostro mantido na propriedade. Na segunda granja os bezerros permaneciam separados das vacas desde o nascimento e recebiam colostro entre 2 e 3 horas de vida. A ingestão do colostro era obrigatoriamente artificial com administração em mamadeira de dois litros do produto fresco, obtido por ordenha da própria mãe. Nas duas propriedades os bezerros recebiam outros dois litros de colostro, oferecidos na mamadeira, próximo às 10 horas de vida.

Durante a fase de lactentes, os bezerros das duas granjas permaneciam em bezerreiro coberto, eram alimentados com dois litros de leite natural duas vezes por dia e recebiam suplementação com ração comercial, feno e sal mineral à vontade. Aos 60 dias de idade eram desmamados e transferidos para piquetes de grama estrela africana (Cynodon plectostachyus), mantendo-se a suplementação com ração comercial, feno e sal mineral.

Amostras de sangue foram obtidas por punção da jugular com uso de agulhas $25 \times 0,7 \mathrm{~mm}$ (PrecisionGlide, BD) para colheita em frasco a vácuo de $10 \mathrm{ml}$ sem anticoagulante (Vacoum II, Labnew). As colheitas foram realizadas seqüencialmente nas seguintes idades: 24-36 horas de vida, 15, 30, 60,
90, 120, 150 e 180 dias de vida. O soro foi obtido por centrifugação após a retração do coágulo e conservado por congelamento a $20^{\circ} \mathrm{C}$ negativos até o momento das análises.

A concentração da proteína total foi determinada pelo método do biureto (GORNAL; BARDAWILL; DAVID, 1949) utilizando-se reagentes comerciais específicos (Proteínas Totais, Bioclin) e leitura espectrofotométrica (Bio 2000, Bioplus). As concentrações das frações protéicas albumina (Alb), alfa 1, alfa 2 beta e gamaglobulinas (gama) foram determinadas por eletroforese (KREMERS; BRIERE; BATSAKIS, 1967), empregando-se gel de agarose comercial (Celmgel, CELM), tampão Tris com pH 9,5 e corrida eletroforética por 20 minutos em corrente de 100V (Sistema SE-250, CELM). Após o procedimento, o gel foi corado com negro de amido $2 \%$ e descorado com ácido acético 5\%. A proporção de cada fração protéica foi estabelecida por meio do programa de informática SDS-60 (CELM) após leitura realizada em scanner. A concentração das globulinas foi calculada pelo somatório de sua frações. A relação albumina:globulina foi calculada por meio da divisão entre as suas concentrações.

A concentração sérica das imunoglobulinas $G$ (IgG) foi estimada pela técnica de turvação pelo sulfato de zinco, conforme o método empregado por Pfeiffer et al. (1977) com modificações. Adicionouse $0,1 \mathrm{~mL}$ de soro a $6 \mathrm{~mL}$ de uma solução contendo $208 \mathrm{mg}$ de $\mathrm{ZnSO}_{4} \cdot 7 \mathrm{H}_{2} \mathrm{O}$ por litro de água destilada. Após uma hora em repouso, a absorbância da mistura foi mensurada por espectrofotometria (E225-D, CELM) em comprimento de onda de $620 \mathrm{~nm}$. Devido à instabilidade da solução, foram realizadas três leituras e considerada a média final. A quantidade de IgG foi estimada com o uso de uma curva padrão previamente traçada com concentrações conhecidas de IgG bovina (Single Radial Immunodiffusion Kit; VRMD, EUA), a saber: zero (soro fetal bovino), 400, $800,1.600$ e $3.200 \mathrm{mg} / \mathrm{dL}$. As amostras que superaram o valor estimado de $3.200 \mathrm{mg} / \mathrm{dL}$ foram processadas novamente após diluição do soro em água destilada na proporção de 1:1. 
O comportamento das variáveis em relação à idade foi avaliado por meio de análise de variâncias de medidas repetidas, considerando cada raça em separado. No caso da concentração de gama, os efeitos da raça, da faixa etária e a interação entre os dois fatores foram testados por meio de análise de variâncias de medidas repetidas bifatorial. O teste de Tukey foi empregado para a comparação entre as médias, admitindo-se uma probabilidade de erro de 5\%. Foram estabelecidos os coeficientes de correlação entre as variáveis estudadas, empregando-se o teste de Pearson (CURI, 1998).

\section{Resultados e Discussão}

Todas as variáveis do proteinograma investigadas variaram de acordo com a idade obedecendo a um padrão fisiológico e, de forma geral, o comportamento foi parecido em ambas as raças (Tabela 1). A maior distinção entre as raças foi observada para a concentração de gama, caracterizando as diferenças fisiológicas mais importantes entre taurinos e zebuínos. A variação da concentração sérica da PT foi influenciada principalmente pelas concentrações da Alb e da gama, frações protéicas com concentrações mais elevadas na circulação. As variações de alfa 1, alfa 2 e beta exerceram relativamente pouca influência porque essas frações estão presentes em concentrações menores.

Tabela 1. Valores médios e desvios-padrão $(\mathrm{x} \pm \mathrm{s})$ de proteínas séricas totais $(\mathrm{PT})$, albumina $(\mathrm{Alb})$, gamaglobulinas (gama), imunoglobulina $\mathrm{G}$ ( $\operatorname{IgG}$ ) e relação albumina:globulina $(\mathrm{A}: \mathrm{G})$ em bezerros sadios das raças Nelore ( $\mathrm{n}=30$ ) e Holandesa $(\mathrm{n}=20)$ nos primeiros 180 dias de vida.

\begin{tabular}{|c|c|c|c|c|c|}
\hline Idade & $\begin{array}{c}\text { PT } \\
(\mathrm{g} / \mathrm{dL})\end{array}$ & $\begin{array}{c}\text { Alb } \\
(\mathrm{g} / \mathrm{dL})\end{array}$ & $\begin{array}{l}\text { gama } \\
(\mathrm{g} / \mathrm{dL})\end{array}$ & $\begin{array}{c}\text { IgG } \\
(\mathrm{g} / \mathrm{dL})\end{array}$ & $A: G$ \\
\hline & \multicolumn{5}{|c|}{ Nelore } \\
\hline 24 a $36 \mathrm{~h}$ & $7,20 \pm 0,78^{a}$ & $2,42 \pm 0,41^{\mathrm{d}}$ & $3,03 \pm 0,79^{a}$ & $3,75 \pm 0,60^{\mathrm{a}}$ & $0,52 \pm 0,13^{f}$ \\
\hline $15 \mathrm{~d}$ & $6,53 \pm 0,49^{b}$ & $3,17 \pm 0,25^{\mathrm{c}}$ & $1,50 \pm 0,37^{\mathrm{b}}$ & $3,00 \pm 0,49^{b}$ & $0,95 \pm 0,16^{\mathrm{e}}$ \\
\hline $30 \mathrm{~d}$ & $6,11 \pm 0,36^{\mathrm{bc}}$ & $3,49 \pm 0,27^{b}$ & $0,90 \pm 0,18^{\mathrm{cd}}$ & $2,56 \pm 0,32^{\mathrm{c}}$ & $1,34 \pm 0,17^{\mathrm{c}}$ \\
\hline $60 \mathrm{~d}$ & $5,99 \pm 0,40^{\mathrm{bc}}$ & $3,63 \pm 0,28^{\mathrm{ab}}$ & $0,67 \pm 0,15^{\mathrm{d}}$ & $2,25 \pm 0,28^{\mathrm{d}}$ & $1,56 \pm 0,19^{b}$ \\
\hline $90 \mathrm{~d}$ & $5,96 \pm 0,33^{\mathrm{bc}}$ & $3,78 \pm 0,24^{\mathrm{a}}$ & $0,72 \pm 0,19^{d}$ & $2,12 \pm 0,32^{\mathrm{d}}$ & $1,76 \pm 0,25^{\mathrm{a}}$ \\
\hline $120 \mathrm{~d}$ & $6,19 \pm 0,31^{\mathrm{b}}$ & $3,59 \pm 0,26^{\mathrm{ab}}$ & $1,02 \pm 0,25^{\mathrm{c}}$ & $2,59 \pm 0,50^{\mathrm{c}}$ & $1,41 \pm 0,25^{\mathrm{c}}$ \\
\hline $150 \mathrm{~d}$ & $6,00 \pm 0,34^{\mathrm{bc}}$ & $3,27 \pm 0,32^{\mathrm{c}}$ & $1,23 \pm 0,29^{\mathrm{b}}$ & $2,67 \pm 0,68^{b}$ & $1,22 \pm 0,25^{\mathrm{d}}$ \\
\hline \multirow[t]{2}{*}{$180 \mathrm{~d}$} & $5,81 \pm 0,38^{c}$ & $3,08 \pm 0,27^{\mathrm{c}}$ & $1,31 \pm 0,27^{\mathrm{b}}$ & $2,85 \pm 0,44^{\mathrm{bc}}$ & $1,15 \pm 0,19^{d}$ \\
\hline & \multicolumn{5}{|c|}{ HPB } \\
\hline 24 a $36 \mathrm{~h}$ & $8,00 \pm 1,08^{b c}$ & $3,57 \pm 0,49^{\mathrm{c}}$ & $2,39 \pm 1,08^{\mathrm{a}}$ & $2,62 \pm 0,63^{\mathrm{cd}}$ & $0,94 \pm 0,58^{\mathrm{b}}$ \\
\hline $15 \mathrm{~d}$ & $8,17 \pm 1,27^{\mathrm{ab}}$ & $3,93 \pm 0,56^{\mathrm{bc}}$ & $1,77 \pm 0,80^{\mathrm{bc}}$ & $2,25 \pm 0,65^{\mathrm{d}}$ & $0,98 \pm 0,26^{\mathrm{b}}$ \\
\hline $30 \mathrm{~d}$ & $7,27 \pm 0,98^{c}$ & $4,06 \pm 0,55^{\mathrm{b}}$ & $1,12 \pm 0,37^{\mathrm{d}}$ & $2,96 \pm 0,49^{a}$ & $1,29 \pm 0,21^{\mathrm{a}}$ \\
\hline $60 \mathrm{~d}$ & $7,94 \pm 0,72^{\mathrm{bc}}$ & $4,73 \pm 0,40^{\mathrm{a}}$ & $1,17 \pm 0,38^{\mathrm{d}}$ & $3,32 \pm 0,39^{a}$ & $1,53 \pm 0,34^{\mathrm{a}}$ \\
\hline $90 \mathrm{~d}$ & $7,83 \pm 0,75^{\mathrm{bc}}$ & $4,59 \pm 0,21^{\mathrm{a}}$ & $1,33 \pm 0,53^{\mathrm{cd}}$ & $2,96 \pm 0,54^{\mathrm{ab}}$ & $1,45 \pm 0,22^{\mathrm{a}}$ \\
\hline $120 \mathrm{~d}$ & $7,86 \pm 0,66^{b}$ & $4,45 \pm 0,37^{a}$ & $1,53 \pm 0,59^{\mathrm{bcd}}$ & $2,84 \pm 0,62^{\mathrm{b}}$ & $1,35 \pm 0,27^{\mathrm{a}}$ \\
\hline $150 \mathrm{~d}$ & $8,16 \pm 0,68^{\mathrm{a}}$ & $4,52 \pm 0,36^{\mathrm{a}}$ & $1,73 \pm 0,53^{\mathrm{bc}}$ & $3,14 \pm 0,49^{\mathrm{ab}}$ & $1,27 \pm 0,22^{\mathrm{a}}$ \\
\hline $180 \mathrm{~d}$ & $8,98 \pm 0,86^{\mathrm{a}}$ & $4,86 \pm 0,49^{a}$ & $2,03 \pm 0,53^{\mathrm{ab}}$ & $3,19 \pm 0,48^{\mathrm{ab}}$ & $1,20 \pm 0,18^{\mathrm{ab}}$ \\
\hline
\end{tabular}

${ }^{a, b}$ letras diferentes na mesma coluna indicam diferença significativa $(p<0,05)$ entre as idades em cada raça em separado.

Fonte: Elaboração dos autores. 
A separação eletroforética das frações alfa 1 e alfa 2 ficou evidente no gel dos bezerros de ambas as raças, o que contraria o conceito de que, nos bovinos, é geralmente difícil separar essas frações e, por isso, as alfaglobulinas são usualmente apresentadas em conjunto (KANEKO, 1997). Nos bezerros da raça Nelore, as concentrações de alfa 1 variaram de $0,24 \pm 0,06$ a $0,41 \pm 0,10 \mathrm{~g} / \mathrm{dL}$, as de alfa 2 variaram de $0,36 \pm 0,07$ a $0,64 \pm 0,05 \mathrm{~g} /$ $\mathrm{dL}$ e as de beta entre $0,56 \pm 0,07$ e $0,98 \pm 0,13 \mathrm{~g} /$ dL. Ao longo dos primeiros seis meses de vida as alfa 1 e as betaglobulinas se reduziram e as alfa 2 se elevaram com o avançar da idade. As bezerras da raça Holandesa apresentaram variações de 0,18 $\pm 0,06$ a $0,54 \pm 0,18 \mathrm{~g} / \mathrm{dL}$, de $0,69 \pm 0,10$ a 0,88 $\pm 0,14 \mathrm{~g} / \mathrm{dL}$ e de $0,67 \pm 0,09$ a $1,14 \pm 0,22 \mathrm{~g} / \mathrm{dL}$ para as concentrações séricas de alfa 1 , alfa 2 e beta, respectivamente. Nesses animais as betaglobulinas também se reduziram com o avançar da idade, mas as alfaglobulinas não exibiram um padrão de variação definido nos seis primeiros meses de vida. Esses resultados são, de forma geral, coerentes com os observados por outros autores que estudaram bezerros Nelore (AMORIM, 2002; COSTA et al., 2008) ou bezerros da raça Holandesa (BORGES et al., 2001; FEITOSA et al., 2001a; COSTA et al., 2007) e caracterizam que, ao contrário da albumina e das gamaglobulinas, essas três frações protéicas experimentam variações fisiológicas de baixa magnitude em sua concentração no início da vida.

Os valores de Alb são mais baixos ao nascimento e se elevam nos primeiros dois meses de vida, refletindo um incremento da capacidade de síntese dessa proteína relacionado à idade (KANEKO, 1997). Os valores de gama, ao contrário, são elevados após a absorção das imunoglobulinas do colostro e se reduzem ao longo do primeiro mês de vida em virtude da distribuição, degradação ou utilização desses anticorpos representativos da imunidade passiva (BARRINGTON; PARISH, 2001; TIZARD, 2002). A relação entre a albumina e as globulinas (A:G) ilustra com propriedade esses dois eventos, sendo menor do que um no segundo dia de vida e se invertendo já ao final do primeiro mês (Tabela 1).

Considerando exclusivamente os resultados nos bezerros ao término do primeiro dia de vida, a concentração de gama no soro se correlacionou fortemente com as concentrações de PT ( $r=0,887$; $\mathrm{p}<0,001)$ e de IgG estimada pelo método de turvação pelo sulfato de zinco ( $\mathrm{r}=0,829 ; \mathrm{p}<0,001)$, o que reforça que esses componentes do soro sanguíneo podem ser empregados como indicadores confiáveis do sucesso ou do insucesso da TIP em bezerros (MORAES et al., 1997; FEITOSA et al., 2001b; COSTA et al., 2008).

A TIP foi bem sucedida, de forma geral, nos bezerros das duas raças, independentemente do tipo de manejo adotado para a ingestão do colostro. Admitindo o valor crítico de $1.000 \mathrm{mg} / \mathrm{dL}$ para a concentração sérica de $\operatorname{IgG}$ como o indicador de sucesso ou insucesso da TIP em bezerros (BARRINGTON; PARISH, 2001; McGUIRK; COLLINS, 2004; GODDEN, 2008), somente duas bezerras da raça Holandesa apresentaram falha na TIP exibindo $200 \mathrm{mg} / \mathrm{dL}$ e $970 \mathrm{mg} / \mathrm{dL}$ como concentrações séricas de gama ao término do primeiro dia de vida. A causa para essa condição permanece não esclarecida uma vez que nenhum dos principais fatores de risco incriminados como causadores estava presente. As bezerras apresentavam boa vitalidade ao nascimento e se mantiveram alertas ao longo do primeiro dia de vida, as suas mães não eram primíparas, não houve eliminação precoce de colostro por gotejamento espontâneo em volume apreciável e a primeira mamada voluntária do colostro ocorreu por volta das duas horas de vida sem dificuldades ou necessidade de auxílio.

Duas possibilidades podem explicar a condição nesses indivíduos: a concentração colostral reduzida de IgG e a absorção intestinal pouco eficiente. A segunda hipótese parece menos provável porque as bezerras nasceram de partos eutócicos. A principal causa de ineficiência da absorção 
intestinal de IgG é o estado de acidose mista mais intenso exibido ao nascimento e cuja correção é mais demorada ao longo do primeiro dia de vida (BESSER; SZENCI; GAY, 1990). Essa condição é uma consequência natural do parto distócico e o bezerro acometido manifesta baixa vitalidade ao nascimento e apatia durante as primeiras horas de vida enquanto perdurar o desequilíbrio (BENESI, 1993). A primeira hipótese parece mais provável. De fato, como demonstrado em alguns estudos, as concentrações de IgG no colostro podem variar consideravelmente em vacas leiteiras devido ao grande volume produzido (SOARES FILHO et al., 2001; BARBOSA et al., 2003; McGUIRK; COLLINS, 2004; GODDEN, 2008). Nas vacas de corte isso seria menos provável porque o volume de colostro é menor e a concentração de IgG tende ser maior e a não variar tanto (WEAVER et al., 2000; GODDEN, 2008; ROCHA et al., 2009). Apesar da falha na TIP, as bezerras não adoeceram e se desenvolveram sem distinção das demais. Isso é reflexo, provavelmente, das práticas de higiene adequadas mantidas no bezerreiro.
Considerando os resultados da primeira colheita, a concentração média de gama foi maior no soro dos bezerros Nelore $(\mathrm{p}<0,001)$ (Figura 1) e a variabilidade foi maior no soro das bezerras Holandesas (Tabela 1). Isso é reflexo de diferenças fisiológicas raciais e de manejo, no que se refere à forma de ingestão do colostro. O risco de insucesso da TIP é reduzido nos bezerros de corte (MACHADO NETO et al., 1997; COSTA et al., 2008; WALDNER; ROSENGREN, 2009) e tende a ser maior nos bezerros leiteiros, porque as vacas leiteiras, e particularmente as da raça Holandesa, podem produzir colostro com concentração reduzida de IgG (WEAVER et al., 2000; GODDEN, 2008). Além disso, o manejo artificial de fornecimento do colostro, adotado na maioria das granjas leiteiras, pode gerar erros contribuindo para a falha parcial ou total da TIP (BORGES et al., 2001; FEITOSA et al., 2003; RIZZOLI et al., 2006).

Figura 1. Variação da concentração sérica de gamaglobulinas em bezerros das raças Nelore e Holandesa nos primeiros seis meses de vida. $(*=\mathrm{p}<0,001)$.

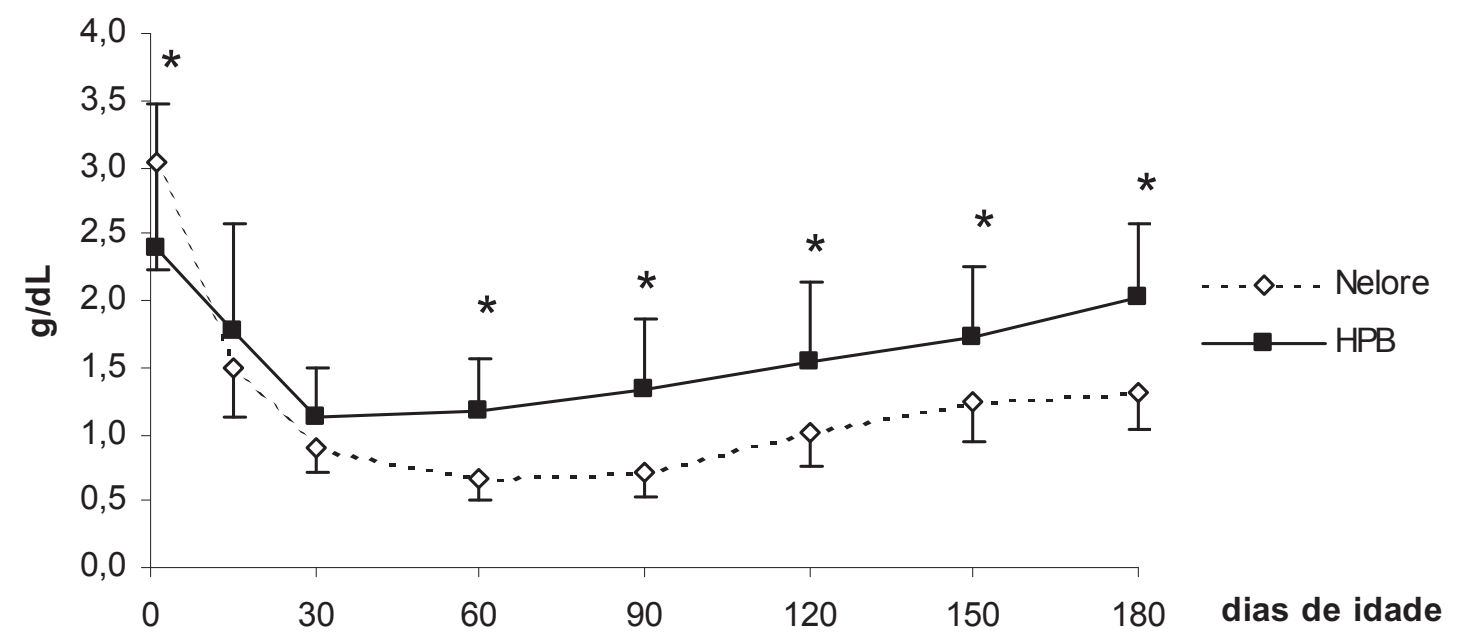

Fonte: Elaboração dos autores. 
Rotinas diferentes de fornecimento do colostro eram adotadas nas duas granjas leiteiras cujas bezerras participaram do estudo. A permanência do bezerro recém-nascido em contato com a mãe durante as primeiras horas e a mamada natural do colostro é uma prática que, apesar de fisiológica, vem sendo desencorajada, principalmente porque não se tem controle sobre o volume de colostro efetivamente ingerido (WEAVER et al., 2000; McGUIRK; COLLINS, 2004; GODDEN, 2008). As concentrações de gama no segundo dia de vida não chegaram a diferir $(\mathrm{p}=0,085)$ entre as bezerras que permaneceram com as suas mães $(1,98 \pm 0,92 \mathrm{~g} / \mathrm{dL})$ e as que foram separadas logo após o nascimento $(2,81 \pm 1,11 \mathrm{~g} / \mathrm{dL})$. Mas, de fato, as duas bezerras que apresentaram falha na TIP mamaram o colostro na própria mãe, o que reforça o conceito de que essa prática pode causar algum insucesso no caso da raça Holandesa.

A ingestão de um volume total de quatro litros de colostro até as seis horas de vida vem sendo indicada atualmente, e se tornando mais popular na América do Norte, como uma medida capaz de garantir o sucesso da TIP em bezerros leiteiros (WEAVER et al., 2000; McGUIRK; COLLINS, 2004; GODDEN, 2008; CORTESE, 2009). No Brasil, como é o caso das granjas estudadas, ainda predomina a prática da ingestão de um volume total de dois litros de colostro nas primeiras horas de vida (BORGES et al., 2001; FEITOSA et al., 2003; RIZZOLI et al., 2006). Com base nos resultados, pode-se admitir que o manejo de oferta de colostro adotado nas granjas estudadas foi, de forma geral, adequado. Entretanto, é incontestável que a ingestão inicial de um volume maior do que dois litros poderia evitar falhas na TIP naqueles casos em que o colostro possui concentração mais reduzida de IgG.

A variação da concentração sérica de gama relacionada à idade é muito bem representada por uma curva e algumas diferenças foram observadas para as duas raças estudadas (Figura 1). Os valores mais elevados no segundo dia de vida experimentam uma redução porque as imunoglobulinas absorvidas do colostro são distribuídas para a luz intestinal (BARRINGTON; PARISH, 2001), degradadas ou utilizadas nos processos de defesa imunológica. Como proteínas estranhas que são no organismo dos bezerros, a suameia-vidaénormalmentereduzida, em torno de 16 a 28 dias para a IgG (CHASE; HURLEY; REBER, 2008). Sob condições desfavoráveis do ambiente e do manejo com exposição intensa aos microrganismos, mais acentuada deverá ser a curva decrescente porque essas proteínas participam dos mecanismos de defesa imune e desaparecem da circulação (TIZARD, 2002). A menor concentração foi observada aos 30 dias de vida nas bezerras da raça Holandesa e aos 60 dias de idade nos bezerros Nelore (Tabela 1).

A síntese endógena de imunoglobulinas provoca uma nova curva crescente na concentração sérica de gama, refletindo o aumento da capacidade de resposta ativa pelo sistema imunológico do bezerro jovem (CHASE; HURLEY; REBER, 2008). Este é o evento particularmente distinto nas duas raças estudadas. Nas bezerras Holandesas a curva crescente de concentração se estabeleceu a partir dos 60 dias de vida, e o segundo mês de vida representou o intervalo de tempo crítico no qual a concentração se manteve com os valores mais reduzidos. Nos bezerros da raça Nelore a concentração de gama começou a se elevar somente a partir dos 90 dias de idade e os valores mais baixos se mantiveram ao longo do segundo e do terceiro mês de vida (Figura 1). Os valores de gama foram sempre maiores nas bezerras Holandesas a partir dos 60 dias de vida $(\mathrm{p}<0,001)$.

A variação das concentrações de gama observada nas diferentes idades para as bezerras da raça Holandesa é condizente, de forma geral, com as obtidas em outros estudos (MORAES et al., 1997; FEITOSA et al., 2001a, 2003; BORGES et al., 2001; PAULETTI et al., 2002; LEAL et al., 2003; COSTA et al., 2007), reforçando que a produção ativa de anticorpos é precoce nos indivíduos dessa raça. A curva de variação observada para os bezerros da raça Nelore é muito parecida, por sua 
vez, com as obtidas por outros autores (AMORIM, 2002; COSTA et al., 2008), o que indica que os bezerros dessa raça são um pouco mais tardios para desenvolverem capacidade de imunidade humoral ativa. Comparações entre bezerros Nelore e das raças Canchim (MACHADO NETO et al., 2004) ou Limousin (COSTA et al., 2008) reforçam essa evidência, reafirmando a existência de diferenças fisiológicas entre zebuínos e taurinos.

Considera-se que os bezerros alcançam o desenvolvimento pleno de atividade do sistema imunológico aos seis meses de idade, quando são capazes de responder de maneira similar aos adultos (CHASE; HURLEY; REBER, 2008; CORTESE, 2009). A maior ou menor precocidade para o desenvolvimento da imunidade ativa pode variar entre os bezerros sob influência da presença dos anticorpos maternos transferidos passivamente. Bezerros que experimentam falha na TIP iniciam a produção própria de imunoglobulinas mais cedo do que os bezerros com sucesso na TIP (RIBEIRO et al., 1983; MORAES et al., 1997; BORGES et al., 2001; FEITOSA et al., 2003). Por um mecanismo ainda não completamente esclarecido, os anticorpos de origem materna em altas concentrações inibem a síntese endógena de imunoglobulinas pelo bezerro jovem (BARRINGTON; PARISH, 2001; PAULETTI et al., 2002; CHASE; HURLEY; REBER, 2008). De fato, os bezerros Nelore possuíam concentração maior de gama no segundo dia de vida. No entanto, aos 15 e 30 dias de vida as concentrações médias não diferiram nas duas raças. $\mathrm{O}$ valor médio de gama mais reduzido das bezerras Holandesas (1,12 g/dL aos 30 dias de idade) foi quase duas vezes maior do que o dos bezerros Nelore $(0,67 \mathrm{~g} / \mathrm{dL}$ aos 60 dias de idade). Esse mecanismo não pode ser admitido, portanto, como explicação para a diferença observada entre as raças.

A concentração da gama na circulação, como é o caso desse estudo, indica de forma inespecífica a capacidade global de produção de anticorpos pelo indivíduo, e permite interpretações sobre a resposta humoral unicamente. As diferenças observadas nesse estudo, ainda que tenham se mantido até os seis meses de idade, não sustentam a hipótese de que os bezerros Nelore possam ser mais susceptíveis a infecções porque os mecanismos de defesa que garantem a saúde não se restringem à imunidade humoral. De fato, todos os bezerros das duas raças permaneceram aparentemente saudáveis durante todo o período de acompanhamento.

Ainda que o fator racial possa, por si só, determinar as diferenças observadas, no caso dos bezerros estudados deve-se considerar que o tipo de manejo adotado pode ter contribuído também para influenciar os resultados. No manejo intensivo, como é o caso dos bezerreiros de granjas leiteiras, a exposição constante e rotineira aos microrganismos, patogênicos ou não, cria uma condição de desafio mais intensa e prolongada do que aquela normalmente enfrentada pelos bezerros manejados extensivamente. É lógico admitir, portanto, que, mesmo sob condições ótimas de higiene, as bezerras Holandesas tenham experimentado estimulação antigênica naturalmente maior do que os bezerros Nelore.

Em suma, os componentes do proteinograma sérico variam fisiologicamente de acordo com a idade, exibindo, de forma geral, um comportamento parecido nos bezerros Nelore e Holandeses. A variação etária da concentração de gamaglobulinas apresentou-se como a distinção mais importante entre as raças, caracterizando que o desenvolvimento da capacidade de imunidade humoral ativa é, de fato, mais tardio nos bezerros Nelore, condição que não parece determinar, entretanto, consequências sobre a saúde dos bezerros. Esses resultados reafirmam evidência anterior e reforçam a ideia de que o assunto deve ser melhor estudado. As diferenças fisiológicas entre taurinos e zebuínos poderiam ser melhor esclarecidas por meio de estudos realizados em ambientes controlados e que avaliassem a capacidade do sistema imunológico de maneira mais abrangente, incluindo a resposta imune humoral específica e a imunidade mediada por células. 


\section{Agradecimentos}

À Fundação ARAUCÁRIA pelo apoio financeiro (protocolo $n^{\text {o }} 4662$ Edital: 05/2003).

O protocolo experimental foi aprovado pelo Comitê de Ética em Experimentação Animal da UEL (CEEA/UEL) sob o número de registro 14/05.

\section{Referências}

AMORIM, R. M. Valores séricos e hepáticos de elementos minerais, atividade sérica da ceruloplasmina, hemograma, proteinograma e metabolismo oxidativo dos neutrófilos em bezerros da raça Nelore, nascidos de mães com nutrição adequada ou inadequada em cobre e zinco. 2002. Tese (Doutorado em Clínica Veterinária) - Faculdade de Medicina Veterinária e Zootecnia. Universidade Estadual Paulista, Botucatu.

BARBOSA, C. P.; BENEDETTI, E.; SILVA, D. A. O.; TAKETOMI, E. A.; GUIMARÃES, E. C. Absorção de imunoglobulinas $\mathrm{G}(\mathrm{IgG})$ do colostro pelo bezerro recémnascido e suas concentrações na glândula mamária. Revista Brasileira de Ciência Veterinária, v. 10, n. 2, p. 67-71, 2003.

BARRINGTON, G. M.; PARISH, S. M. Bovine neonatal immunology. Veterinary Clinics of North America: Small Animal Practice, Philadelphia, v. 17, n. 3, p. 463-476, 2001.

BENESI, F. J. Síndrome asfixia neonatal dos bezerros. Importância e avaliação crítica. Arquivos da Escola de Medicina Veterinária da UFBA, v. 16, n. 1, p. 38-48, 1993.

BESSER, T. E.; SZENCI, O.; GAY, C. C. Decreased colostral immunoglobulin absorption in calves with postnatal respiratory acidosis. Journal of the American Veterinary Medical Association, Illinois, v. 196, n. 8, p. 1239-1243, 1990.

BORGES, A. S.; FEITOSA, F. L. F.; BENESI, F. J.; BIRGEL, E. H.; MENDES, L. C. N. Influência da forma de administração e da quantidade fornecida de colostro sobre a concentração de proteína total e de suas frações eletroforéticas no soro sanguíneo de bezerros da raça Holandesa. Arquivo Brasileiro de Medicina Veterinária e Zootecnia, Belo Horizonte, v. 53, n. 5, p. 629-634, 2001.

CHASE, C. C. L.; HURLEY, D. J.; REBER, A. J. Neonatal immune development in the calf and its impact on vaccine response. Veterinary Clinics of North America: Small Animal Practice, Philadelphia, v. 24, n. 1, p. 87-104, 2008.
CORTESE, V. S. Neonatal immunology. Veterinary Clinics of North America: Small Animal Practice, Philadelphia, v. 25, n. 2, p. 221-227, 2009.

COSTA, J. N.; PEIXOTO, A. P. C.; KOHAYAGAWA, A.; SOUZA, T. S. Proteinograma sérico de bezerras da raça Holandesa do nascimento aos 150 dias de idade. Revista Brasileira de Saúde e Produção Animal, Salvador, v. 8, n. 4, p. 267-275, 2007.

COSTA, M. C.; FLAIBAN, K. K. M. C.; CONEGLIAN, M. M.; FEITOSA, F. L. F.; BALARIN, M. R. S.; LISBÔA, J. A. N. Transferência de imunidade passiva em bezerros das raças Nelore e Limousin e proteinograma sérico nos primeiros quatro meses de vida. Pesquisa Veterinária Brasileira, Seropédica, v. 28, n. 9, p. 410-416, 2008.

CURI, P. R. Metodologia e análise da pesquisa em ciências biológicas. 2. ed. Botucatu: Gráfica e Editora Tipomic, 1998. $263 \mathrm{p}$.

FAGLIARI, J. J.; SANTANA, A. E.; LUCAS, F. A.; CAMPOS FILHO, E.; CURI, P. R. Constituintes sangüíneos de bovinos recém-nascidos das raças Nelore (Bos indicus) e Holandesa (Bos taurus) e de bubalinos (Bubalis bubalus) da raça Murrah. Arquivo Brasileiro de Medicina Veterinária e Zootecnia, Belo Horizonte, v. 50, n. 3, p. 253-262, 1998.

FEITOSA, F. L. F.; BIRGEL, E. H.; MIRANDOLA, R. M. S.; PERRI, S. H. V. Diagnóstico de falha de transferência de imunidade passiva em bezerros através da determinação de proteína total e de suas frações eletroforéticas, imunoglobulinas $\mathrm{G}$ e $\mathrm{M}$ e da atividade da gama glutamiltransferase no soro sangüíneo. Ciência Rural, Santa Maria, v. 31, n. 2, p. 251-255, 2001 b.

FEITOSA, F. L. F.; BIRGEL, E. H.; MIRANDOLA, R. M. S.; PERRI, S. H. V. Proteinograma sérico de bezerros holandeses do nascimento até um ano de vida. Revista Brasileira de Ciência Veterinária, v. 8, n. 2, p. 105-108, 2001a.

FEITOSA, F. L. F.; BORGES, A. S.; BENESI, F. J.; BIRGEL, E. H.; MENDES, L. C. N.; PEIRÓ, J. R. Concentração de imunoglobulinas $\mathrm{G}$ e $\mathrm{M}$ no soro sanguíneo de bezerros da raça Holandesa até os 90 dias de idade. Brazilian Journal of Veterinary Research and Animal Science, São Paulo, v. 40, p. 26-31, 2003. Suplemento 1.

GODDEN, S. Colostrum management for dairy calves. Veterinary Clinics of North America: Small Animal Practice, Philadelphia, v. 24, n. 1, p. 19-39, 2008.

GORNAL, A. G.; BARDAWILL, C. J.; DAVID, M. M. Determination of serum proteins by means of the biuret reaction. Journal of Biological Chemistry, v. 177, n. 3, p. 751-766, 1949. 
KANEKO, J. J. Serum proteins and the dysproteinemia. In: KANEKO, J. J.; HARVEY, J. W.; BRUSS, M. L. (Ed.). Clinical biochemistry of animals. $5^{\text {th }}$ ed. San Diego: Academic Press, 1997. p. 117-138.

KREMERS, B.; BRIERE, R.; BATSAKIS, J. G. Reflectance densitometry of cellulose acetate protein eletrophoresis. American Journal of Medical Technology, v. 33, n. 1, p. 28-34, 1967.

LEAL, M. L. R.; BENESI, F. J.; LISBÔA, J. A. N.; COELHO, C. S.; MIRANDOLA, R. M. S. Proteinograma sérico de bezerras sadias, da raça holandesa, no primeiro mês pós-nascimento. Brazilian Journal of Veterinary Research and Animal Science, São Paulo, v. 40, n. 2, p. 138-145, 2003.

MACHADO NETO, R.; D'ARCE, R. D. Gamaglobulinas séricas de bezerros recém-nascidos da raça Nelore. Revista da Sociedade Brasileira de Zootecnia, v. 8, n. 1, p. 33-42, 1979.

MACHADO NETO, R.; PACKER, I. U.; BONILHA, L. M.; FIGUEIREDO, L. A.; RAZZOK, A. G.; CÂNDIDO, J.G. Concentração de $\operatorname{IgG}$ sérica em bezerros das raças Nelore, Guzerá, Gir e Caracu. 1. Estatísticas descritivas e causas de variação. Revista Brasileira de Zootecnia, Viçosa, MG, v. 26, n. 5, p. 914-919, 1997.

MACHADO NETO, R.; PACKER, I. U.; PRADO, G. V. B.; BESSI, R.; PAULETTI, P. Colostral immunoglobulins absorption in Canchim and Nelore calves. Revista Brasileira de Zootecnia, Viçosa, MG, v. 33, n. 6, p. 15441547, 2004.

MCGUIRK, S. M.; COLLINS, M. Managing the production, storage, and delivery of colostrums. Veterinary Clinics of North America: Small Animal Practice, Philadelphia, v. 20, n. 3, p. 593-603, 2004.

MORAES, M. P.; WEIBLEN, R.; SILVA, A. M.; TOBIAS, F. L. Evolução da imunidade passiva em fêmeas bovinas da raça Holandesa. Ciência Rural, Santa Maria,v. 27, n. 3, p. 435-440, 1997.

PAULETTI, P.; MACHADO NETO, R.; PACKER, I. U.; BESSI, R. Avaliação de níveis séricos de imunoglobulina, proteína e o desempenho de bezerras da raça holandesa. Pesquisa Agropecuária Brasileira, Brasília, v. 37, n. 1, p. 89-94, 2002.
PFEIFFER, N. E.; McGUIRE, T. C.; BENDEL, R. B.; WEIKEL, J. M. Quantitation of bovine immunoglobulins: comparison of single radial immunodiffusion, zinc sulfate turbidity, serum electrophoresis, and refratometer methods. American Journal of Veterinary Research, v. 38, n. 5, p. 693-698, 1977.

RIBEIRO, M. F. B.; SALCEDO, J. H. P.; BELÉM, P. A. D.; FARIA, J. E. Hipogamaglobulinemia em bezerros. Arquivos Brasileiro de Veterinária e Zootecnia, Belo Horizonte, v. 35, n. 4, p. 537-546, 1983.

RIZZOLI, F. W.; FAGLIARI, J. J.; SILVA, D. G.; SILVA, S. L.; JORGE, R. L. N. Proteinograma e teores séricos de cálcio, fósforo, magnésio e ferro de bezerros recémnascidos que mamaram colostro diretamente na vaca ou em mamadeira. Ars Veterinaria, Jaboticabal, v. 22, n. 3, p. 198-202, 2006.

ROCHA, T. G.; FRANCIOSI, C.; NOCITI, R. P.; SILVA, P. C.; SAMPAIO, A. A. M.; FAGLIARI, J. J. Eletroforetograma das proteínas do soro lácteo de vacas Canchim primíparas e pluríparas. Ciência Animal Brasileira, Goiânia, v. 10, p. 220-225, 2009. Suplemento 1.

SOARES FILHO, P. M.; BELÉM, P. A. D.; RIBEIRO JÚNIOR, J. I.; SALCEDO, J. H. P. Concentrações de imunoglobulina $G$ em colostro de vacas mestiças Holandês-Zebu. Ciência Rural, Santa Maria, v. 31, n. 6, p. 1033-1037, 2001.

TIZARD, I. R. Imunidade no feto e no recém-nascido. In: Imunologia veterinária: uma introdução. 6. ed. São Paulo: Roca, 2002. p. 2 33-246.

WALDNER, C. L.; ROSENGREN, L. B. Factors associated with serum immunoglobulin levels in beef calves from Alberta and Saskatchewan and association between passive transfer and health outcomes. Canadian Veterinary Journal, v. 50, n. 7, p. 275-281, 2009.

WEAVER, D. M.; TYLER, J. W.; VANMETRE, D. C.; HOSTETLER, D. E.; BARRINGTON, G. M. Passive transfer of colostral immunoglobulins in calves. Journal of Veterinary Internal Medicine, v. 14, n. 5, p. 569-577, 2000. 